\title{
THE CURRENT STATUS OF MAPPING IN THE WORLD - SPOTLIGHT ON AUSTRALIA
}

\author{
John C Trinder \\ School of Civil and Environmental Engineering, UNSW SYDNEY NSW 2052, Australia (j.trinder@unsw.edu.au)
}

\author{
Commission IV, WG IV-2
}

KEYWORDS: Global Mapping, Digital, Scale, Australia

\begin{abstract}
:
Prior to 1950, there was very limited mapping in Australia covering only strategic areas. After World War II, the Federal Government funded the small scale mapping of the whole country. This involved the development of the Australian National Spheroid in 1966, the Australian Geodetic Datum in 1966 and 1984 (AGD66 and AGD84) which were replaced by the Australian Geocentric Datum in 1994 (GDA94). The mapping of the country was completed in 1987 with $100 \%$ of the country mapped at 1:100,000 and 1:250,000 although about half of the 1:100,000 are unpublished products. The Federal Government through Geoscience Australia continues to provide digital data, such as the GEODATA 250K (now series 3). Mapping at larger scales is undertaken by the states and territories, including cadastral mapping. This paper will demonstrate the extent of mapping in Australia as part of the current UN global survey of mapping.
\end{abstract}

\section{INTRODUCTION}

Konecny (2013) stated that surveys of the status of mapping around the world were carried out in 1968, 1974, 1980 and 1987, the last survey revealing the status of mapping in 1986 nearly 30 years ago. Further surveys are urgently needed to document whether there has been an improvement in the map coverage. The most recent survey of mapping in Oceania, of which Australia covers the vast majority of area, revealed that $18.3 \%$ had been mapped at a scale of $1: 25,000,24.3 \%$ at $1: 50,000,54 \%$ at $1: 100,000$ and $100 \%$ at $1: 250,000$. This paper will demonstrate the current extent of map coverage in Australia.

Australia's administration is based on a federated system comprising the Federal Government of the Commonwealth of Australia with many overarching sovereign powers, and six states with their own sovereign powers to manage many operational issues related to administration of day-to-day affairs of the states. The states shown in Figure 1 are: New South Wales (NSW), Queensland, South Australia (SA), Tasmania, Victoria and Western Australia (WA). There are also two territories, Australian Capital Territory (ACT) the administration capital of the country which includes the city of Canberra, and Northern Territory. Territories have their own parliaments, but have less autonomy than the states. The administration of record systems pertaining to land ownership, land tenure, land use and land valuation are undertaken by the respective states and territories (Marwick 2013). Surveying and mapping activities are coordinated through the Intergovernmental Committee on Surveying and Mapping (ICSM), which was established in 1988 and replaced the former National Mapping Council (NMC). Membership of ICSM comprises senior representatives of all surveying and mapping agencies in Australia and New Zealand.

Australia is the world's sixth largest land mass with an area of $7,692,024 \mathrm{~km}^{2}$ of which almost one third is in the state of Western Australia. The smallest state is Tasmania with about $68,000 \mathrm{~km}^{2}$, while the ACT covers $2,358 \mathrm{~km}^{2}$. The population of Australia in 2012 was 22.68 million, which is sparse in many parts of the country since a large proportion is desert or subject to desert climates. About $90 \%$ of the population lives along the eastern seaboard. Therefore medium and large scale mapping is only required in limited populated areas of the country.

In order to undertake this survey of the status of mapping, government departments responsible for mapping namely, Geoscience Australia representing the Commonwealth of Australia, and all states and territories were approached to complete the questionnaire. Responses were received from all those contacted with the exception of the Northern Territory. This paper will summarise the results of the responses. In some cases, additional research on the respective web sites was required to extract further information.

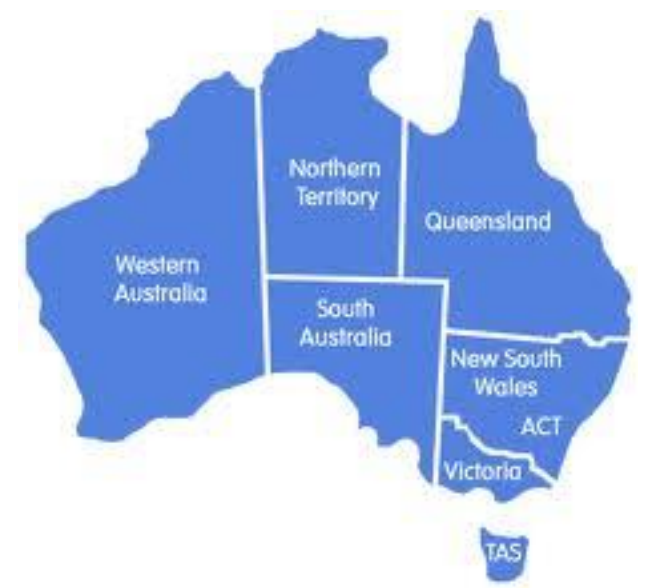

Figure 1 The continent of Australia with the 6 states and 2 territories

The paper will demonstrate the diversity of mapping within Australia which is a function of the administration arrangements around the country. The coverage of medium and large scales is determined by the population density and the number of features in the area. In the Australian Capital Territory, a 1:1,000 map scale is used and the digital details are updated daily. By contrast, in Western Australia where the majority of the population live in the south western corner of the state, only a very small proportion of the state is covered by larger scale maps. Major issues covered by the survey are the map update frequency, methods used for map updating, imagery acquisition, 
orthophoto production, and lidar and DEM coverage, which vary significantly across the country. The paper will also provide some details of cadastral data and the administration arrangements for maintenance of the cadastre by the states and territories. Overall the survey reveals that the major maps scales covering the country continue to be the scales of 1:50,000, 1:100,000 and 1:250,000, with limited coverage of larger scales in the populous areas. It is unlikely that the percentage of large scale maps will increase unless there are further significant increases in population densities.

Table 1 Status of Topographic Mapping in Australia

\begin{tabular}{|c|c|c|c|c|c|c|}
\hline $\begin{array}{l}\text { Jurisdiction - \% } \\
\text { area occupied in } \\
\text { continent on } \\
\text { Australia }\end{array}$ & $\begin{array}{l}1: 10,000 \quad \& \\
\text { larger } \\
\% \text { coverage } \\
\text { Approx. age } \\
\end{array}$ & $\begin{array}{l}1: 25,000 \% \\
\text { coverage } \\
\text { Approx. age }\end{array}$ & $\begin{array}{l}1: 50,000 \\
\% \text { coverage } \\
\text { Approx. } \\
\text { age } \\
\end{array}$ & $\begin{array}{l}1: 100,000 \\
\% \quad \text { coverage } \\
\text { Approx. age }\end{array}$ & $\begin{array}{l}1: 250,000 \\
\% \quad \text { coverage } \\
\text { Approx. age }\end{array}$ & $\begin{array}{ll}1: 500,000 ~ \& ~ & \text { smaller } \\
\% & \text { coverage } \\
\text { Approx. age } & \end{array}$ \\
\hline \multirow{2}{*}{ NSW - 10.4\% } & & $30 \%$ & $32 \%$ & $38 \%$ & - & - \\
\hline & & $5-30 \mathrm{yr}$ & $5-30 \mathrm{yr}$ & $5-30 \mathrm{yr}$ & & \\
\hline \multirow[t]{2}{*}{ QLD-22.5\% } & & $100 \%$ & - & - & - & - \\
\hline & & 0 to 30 years & & & & \\
\hline \multirow[t]{2}{*}{ SA -12.8\% } & $26 \%$ & - & $39 \%$ & - & - & - \\
\hline & & & 12 to $35 \mathrm{yr}$ & & & \\
\hline \multirow[t]{2}{*}{ TAS $-0.9 \%$} & & $100 \%$ & $100 \%$ & & - & - \\
\hline & & 0 to $30 \mathrm{yr}$ & $1-16 \mathrm{yr}$ & & & \\
\hline \multirow[t]{2}{*}{ VIC-3\% } & & $5 \%$ & $100 \%$ & $100 \%$ & - & - \\
\hline & & 2 to $8 \mathrm{yr}$ & 1 to 8 years & & & \\
\hline \multirow[t]{2}{*}{ WA - 32.9\% } & $0.3 \%$ & $0.4 \%$ & $6.4 \%$ & - & - & - \\
\hline & $1-2 \mathrm{yrs}$ & $2-50 \mathrm{yrs}$ & $5-30 \mathrm{yrs}$ & & & \\
\hline \multirow[t]{2}{*}{ ACT $-0.03 \%$} & $100 \%$ & - & - & - & - & - \\
\hline & Updated daily & & & & & \\
\hline $\begin{array}{l}\text { Total for } \\
\text { states/territories }\end{array}$ & $3 \%$ & $26.8 \%$ & $14.3 \%$ & $7 \%$ & & \\
\hline \multirow[t]{2}{*}{ Commonwealth } & & & $32 \%$ & $100 \%$ & $100 \%$ & $100 \%$ \\
\hline & & & & $20-30 \mathrm{yrs}$ & $\begin{array}{l}\text { Regular } \\
\text { updates }\end{array}$ & $\begin{array}{l}\text { Updates when funding } \\
\text { available }\end{array}$ \\
\hline Total & $3.4 \%$ & $26.8 \%$ & $46.3 \%$ & $100 \%$ & $100 \%$ & $100 \%$ \\
\hline
\end{tabular}

\section{RESPONSES TO QUESTIONNAIRE}

Question 1: Scales of topographic digital data and/or map products (or series) produced and maintained \& Question 2: Current Age of Existing Geodata

The status of mapping and approximate ages of the maps are presented in Table 1, although in many cases there is limited information available on the ages of maps, and many maps are 30 or more years old. All current mapping is based on GDA94 (Geocentric Datum of Australia 1994). Since there was very little mapping available prior to World War II a major mapping program was undertaking following the War. The mapping of the whole of the country was completed in 1987 with $100 \%$ mapped at 1:100,000 and 1:250,000 although about half of the 1:100,000 are unpublished products. The only data that is being updated on a regular basis by the Commonwealth is the 1:250,000 series (GEODATA250K) in digital form. Some states/territories are undertaking their own mapping at medium and larger scales with more regular updating as shown in Table 1. It is estimated that $26.8 \%$ of the country has been mapped at $1: 25,000,46.3 \%$ has been mapped at the scale of $1: 50,000$ and $100 \%$ has been mapped at 1:100,000 and 1:250,000. These percentages show significant increases from 1986 in the extent of mapping at the scales of 1:100,000 and larger as described by Konecny (2013) and summarised above.

\section{Question 3) Restrictions on Map Data Distribution}

There are no restrictions to access of map data except there may be a charge for cost of supply. In Western Australia some information related to public assets is restricted.
Question 4) Sale of Maps: Are maps sold to the public free of charge and free to Government departments?

Conditions vary for states/territories and federally. Some states/territories provide digital data free of charge or cost of reproduction, while other states/territories charge the public as well as government departments for supply of data. Charges can be based on per megabyte or per feature. In some cases map products may be priced according to the cost of creating the product.

\section{Question 5) Updating Strategy}

Generally the update frequency is based on mapping of changed features in the digital data that are reflected in the national or state wide databases. In the federal government (Geoscience Australia - GA) the revision is dependent of funding and staffing for each year. The larger scale map series are updated more frequently, and their updates may feed into smaller scale updates.

\section{Question 6) Updating Methodology}

Updating is based on all sources, but mostly from aerial photography. For the smaller scales, satellite images are used extensively.

\section{Question 7) In-house Capabilities of NMAs}

Mostly mapping is done in-house, but outsourcing also applies in some states/territories. The federal department, GA, states that outsourcing is dependent on a balance of the complexity of 
the work to update and the time it takes to complete the work. Some work will be outsourced and others not if the complexity is high and hence internal knowledge would lead to more efficient map production. The time factor is also a consideration: that is, whether the time taken to prepare work packages for outsourcing will be longer than the time taken to complete the activity in-house.

\section{A) National Imagery Acquisition}

\section{Question 8) National Aerial Imagery Program}

There is ample domestic capability in Australia for aerial photography, with some state mapping departments having their own facilities. All states/territories record digital imaging while the federal department also uses analogue images. There is no regular national acquisition of aerial images, but some states/territories acquire regular coverage of their regions.

\section{Question 9) Satellite Imagery Used by NMA}

There is no national satellite program and therefore Australian mapping agencies depend on foreign satellites to source their satellite data, which is used on an as needs basis. NSW acquires satellite imagery of the state on a regular basis.

\section{Question 10) Use of Radar or Lidar}

Lidar is acquired extensively on a project basis over specific areas such as coastal regions, rivers and urban areas for the determination of DEMs with vertical resolution to $1 \mathrm{~m}$. There is limited acquisition of radar data.

\section{Question 11) Lidar DEM}

Lidar data at densities from 1 to $8 \mathrm{pts} / \mathrm{m}^{2}$ are being acquired over large areas federally and in some states/territories eg $60,000 \mathrm{~km}^{2}$ in Queensland.

\section{Question 12) Orthophoto Program}

Digital orthophotos are produced by most states/territories with variable resolutions. Some states/territories acquire $10 \mathrm{~cm}$ pixel size over urban areas and $50 \mathrm{~cm}$ over rural areas. The coverage of orthophotos is not shown in Table 1, because these details were not included in the responses by most states/territories. However there is an increasing provision of digital orthophotos in Australia.

\section{Question 13) National DEM}

National DEMs are available at 9 second derived from 1:100,000 and 1:250,000 scale topographic mapping; 3 second and 1 second DEMs derived from the Shuttle Radar Topography Mission (SRTM). Some states/territories have acquired state-wide DEMs; for example NSW and Victoria have acquired $20 \mathrm{~m}$ DEM, while Victoria also has a $10 \mathrm{~m}$ DEM over $80 \%$ of the state and 1m DEM over Greater Melbourne Metropolitan Area. Other states/territories have acquired DEMs according to their orthophoto production.

\section{Question 14) Interest in 3D technology by NMA}

To the question whether the federal department or states/territories produce or intend to produce 3D urban and rural landscape models and/or product visualization, some responses were yes and others no.

\section{B) National surveying and cadastral coverage}

\section{Question 15) Licensed Surveyors}

All surveyors who undertake cadastral surveys must be registered in the state in which they undertake surveys. The federal government is not responsible for cadastral surveys.

\section{Question 16) Responsibility for Cadastral Mapping and Cadastral Map Coverage}

While the states/territories are responsible for assembling the cadastral data the Public Sector Mapping Authority (PSMA) in Australia assembles various Australian state's jurisdictional data into national datasets.

\section{Question 17) Use of Cadastral Maps}

Most common uses of cadastral maps are for land registration, land titles, conveyancing and taxation.

\section{Question 18) Cadastral Maps and Geodetic Control}

All state cadastral maps are currently referenced to the GDA (Geocentric Datum of Australia), except ACT which operates on a local coordinate system, but transformations to GDA are available.

However, the appropriate geodetic datum is in a transitional stage. By 2015 the Static Datum GDA2020, based on Frame ITRF@2020 will be realised annually. From the 2020 Dynamic Datum GDA, ITRF will be realised continually.

\section{Question 19) Monumentation of Property Boundaries}

The majority of boundaries are monumented in all states/territories.

\section{Question 20) Updating of Cadastral Maps}

In most states/territories survey plans are submitted electronically and changes to titles are introduced into the cadastral maps dynamically soon after the survey has been completed.

\section{Question 21) Number of Cadastral Employees}

There are approximately 2,500 surveyors in Australia with 90\% in private practice and the rest in state/territory government employment.

\section{C) Organisation}

\section{Question 22) National Funding for Mapping}

Generally the answer to this question was yes. The state of Victoria wrote as follows:

Government partially funds the framework mapping. Data and product sales subsidise much of the product range. Image acquisition is via a cooperative arrangement with contributions from purchase partners for acquisition of imagery and production of elevation products over specific project areas.

Western Australia (WA) wrote:

There are some opportunities for collaboration with federal agencies (e.g. Geoscience Australia and Bureau of Meteorology). As context, Landgate (the mapping agency in Western Australia) coordinates the Western Australian Land 
Information System (WALIS) and Community, which is a dynamic partnership of government agencies working with business, education and the general community to manage and promote the State's geographic information. The mission of WALIS is to build networks of people and technology to share land and geographic information, and to continually improve the data's usefulness and accessibility. Hence, WALIS is not a single centralised source of geographic data, but does employ processes and strategies to 'capture once, use many times' geographic infromation. This is further embodied in a Location Information Strategy for WA which aims to enhance the use of location information to improve decision making and community outcomes.

\section{Question 23) Mapping Budget}

The approximate cost of mapping in Queensland (22.5\% of area of Australia) is AUD32 million and in Victoria (3\% of area of Australia) AUD10 million. These figures cannot be extrapolated to the whole of Australia. Geoscience Australia (GA) National Geographic Information Group, as the National Mapping Agency, has an annual budget of approximately AUD8.5 million for the data acquisition and maintenance programs, and production of standard small scale mapping products. This amount does not include any additional work carried out on customised products for clients and does not include any cadastral work.

\section{Question 24) NMA staff}

An accurate figure cannot be provided because the tasks of technical staff have become much broader than simply producing maps. GA has a total of 84 staff, $10 \%$ of whom are administration/project management.

\section{Question 25) Legal Status of Mapping}

The federal government's mapping programs are defined by Commonwealth of Australia Administrative Arrangement Orders and Portfolio Budget Statement. Most state/territory governments have no explicit legislative mandate for topographic data collection and management, but this has been an ongoing function of governments.

\section{Question 26) Form of Map Products Supplied}

The forms vary greatly across the jurisdictions from: $5 \%$ to $40 \%$ hardcopy

$40 \%$ to $100 \%$ digital delivered as digital datasets
$40 \%$ to $75 \%$ digital data downloaded

\section{Question 27) Archival of Geodata}

Some states/territories update their archives on a regular basis every 3 to 6 months, while other states/territories and the federal department do regular updates and archival when major updates or changes occur.

\section{CONCLUSIONS}

The paper gives a brief description of the map coverage in Australia by the federal government and states/territories (excluding the Northern Territory). In comparison with the earlier survey of mapping in Oceania of which Australia is a large component, there have been significant increases in the percentage coverage of maps at scales of 1:25,000 and 1:50,000 and 1:100,000, although some of the 1:100,000 maps are described as unpublished.

All current map products are produced in digital form, but older maps were produced as hardcopy maps. As well, older maps are increasingly becoming out-of-date and without a schedule for their updating. There is a need for the further funding being provided for the updating these maps. Current methods of mapping involve the latest technologies available including aerial digital cameras, satellite images where appropriate, and lidar. The nationwide DEM is inadequate for many purposes, especially for the study of the effects of rises in sea-level, and hence has to be supplemented by new higher density surveys.

\section{References}

Konecny G, 2013 'The International Society for Photogrammetry and Remote Sensing (ISPRS) study on the status of mapping in the world, paper presented to Second High Level Forum on Global Geospatial Information Management, Doha, Qatar, 4 - 6 February 2013, pp1-23.

Marwick B 2013 'A Collaborative Framework to Support a National Land Information Infrastructure in Australia',

Master of Geomatic Engineering thesis, University of Melbourne, pp1-124.

\section{Acknowledgments}

The contributions of the mapping agencies in Australia which responded to the questionnaire are gratefully acknowledged. 